$\frac{48}{8} / 5.950522$

PREPARED FOR THE U.S. DEPARTMENT OF ENERGY, UNDER CONTRACT DE-AC02-76-CHO-3073

PPPL-3117

UC-420,426

PPPL-3117

\title{
IMPROVED CONFINEMENT WITH REVERSED MAGNETIC SHEAR IN TFTR
}

BY

F.M. LEVINTON, M.C. ZARNSTORFF, S.H. BATHA, ET AL.

JULY 1995
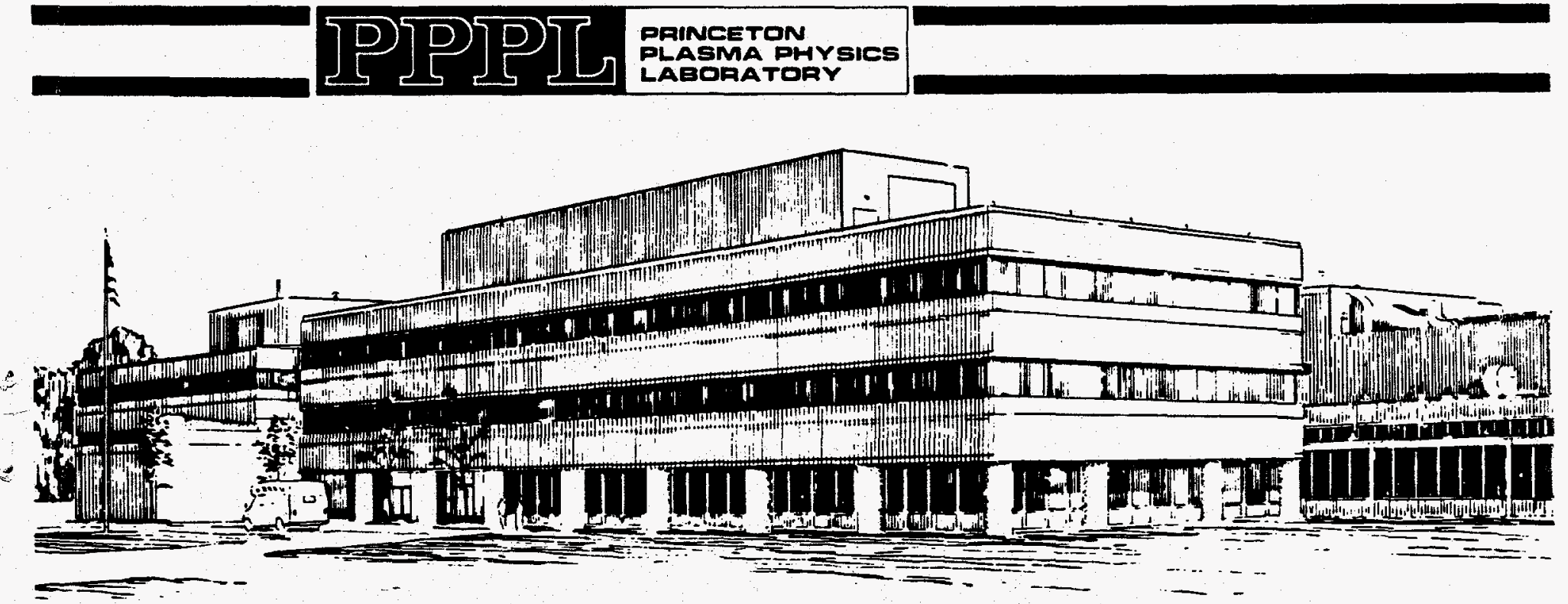

\section{PRINCETON UNIVERSITY, PRINCETON, NEW JERSEY}




\section{NOTICE}

This report was prepared as an account of work sponsored by an agency of the United States Government. Neither the United States Government nor any agency thereof, nor any of their employees, makes any warranty, express or implied, or assumes any legal liability or responsibility for the accuracy, completeness, or usefulness of any information, apparatus, product, or process disclosed, or represents that its use would not infringe privately owned rights. Reference herein to any specific commercial produce, process, or service by trade name, trademark, manufacturer, or otherwise, does not necessarily constitute or imply its endorsement, recommendation, or favoring by the United States Government or any agency thereof. The views and opinions of authors expressed herein do not necessarily state or reflect those of the United States Government or any agency thereof.

\section{NOTICE}

This report has been reproduced from the best available copy. Available in paper copy and microfiche.

Number of pages in this report: 18

DOE and DOE contractors can obtain copies of this report from:

Office of Scientific and Technical Information

P.O. Box 62

Oak Ridge, TN 37831;

(615) 576-8401.

This report is publicly available from the:

National Technical Information Service

Department of Commerce

5285 Port Royal Road

Springfield, Virginia 22161

(703) $487-4650$ 


\section{DISCLAIMER}

Portions of this document may be illegible in electronic image products. Images are produced from the best available original document. 


\title{
Improved Confinement with Reversed Magnetic Shear in TFTR
}

\author{
F. M. Levinton ${ }^{1}$, M. C. Zarnstorff ${ }^{2}$, S. H. Batha ${ }^{1}$, M. Bell $^{2}$, R. E. Bell ${ }^{2}$, R. V. Budny ${ }^{2}$, \\ C. Bush ${ }^{3}$, Z. Chang ${ }^{2}$, E. Fredrickson ${ }^{2}$, A. Janos ${ }^{2}$, H.Park ${ }^{2}$, A. Ramsey ${ }^{2}$, G. L. Schmidt ${ }^{2}$, \\ E. Synakowski², G. Taylor ${ }^{2}$ \\ ${ }^{1}$ Fusion Physics and Technology, Torrance, CA 90503 \\ ${ }^{2}$ Princeton Plasma Physics Laboratory, P.O. Box 451, Princeton, NJ 08543 \\ ${ }^{3}$ Oak Ridge National Laboratory, Oak Ridge, TN 37831
}

(June 7,1995 )

\begin{abstract}
Highly peaked density and pressure profiles in a new operating regime have been observed on the Tokamak Fusion Test Reactor (TFTR). The qprofile has a region of reversed magnetic shear extending from the magnetic axis to $r / a \sim 0.3-0.4$. The central electron density rises from $0.45 \times 10^{20} \mathrm{~m}^{-3}$ to nearly $1.2 \times 10^{20} \mathrm{~m}^{-3}$ during neutral beam injection. The electron particle diffusivity drops precipitously in the plasma core with the onset of the improved confinement mode and can be reduced by a factor of $\sim 50$ to near the neoclassical particle diffusivity level.

52.55.-s, 52.55.Fa, 52.30.Bt
\end{abstract}

DISTRIBUTION OF THIS DOCUMENT IS UNLIMITED

Typeset using REVTEX 
The economic attractiveness of the tokamak as a candidate for a fusion reactor depends on development of a magnetic configuration that has good confinement, stability, and low recirculating power for steady state current drive. This requires a high fraction of self-sustaining bootstrap current that is well aligned with an optimized current density profile for confinement and stability. Recent studies [1] of the optimization of the current density profile suggest that reversed magnetic shear (i.e. a hollow current density profile), is desirable for confinement, stability, and bootstrap alignment. Shear is defined as, $s \equiv(2 V / q)(d q / d \psi)(d \psi / d V) \approx(r / q)(d q / d r)$, where $\psi$ is the enclosed poloidal flux, $V$ is the enclosed volume, $q$ is the safety factor and $r$ is the minor radius. Shear is thought to be important because it can stabilize some classes of microinstabilities such as trapped electron modes [2], a candidate to explain the observed anomalous electron transport in tokamaks. Reversed magnetic shear can also stabilize some magnetohydrodynamic (MHD) instabilities such as ballooning modes [3] and resistive tearing modes. A further benefit, if improved core confinement can be attained, is a high pressure gradient that would generate a strong off-axis bootstrap current, and sustain the hollow current density profile. This scenario may lead to an attractive concept for a steady state tokamak reactor [4]. Most tokamaks operate with inductive current drive which will normally produce peaked current density profiles at the magnetic axis due to the strong dependence of the plasma conductivity on the electron temperature. Only by non-inductive current drive or transient techniques can a hollow current density profile be generated. This has been done in several experiments such as Tore-Supra [5] using lower hybrid current drive (LHCD) and JET [6,7] using pellet injection. These experiments have reported improved performance that could be attributed to reversed shear.

Recent experiments on the Tokamak Fusion Test Reactor (TFTR) [8] have demonstrated a reversed shear configuration. With measurements of $q(R, t)$ from the motional Stark effect (MSE) $[9,10]$ diagnostic providing good temporal and spatial resolution, a correlation of the effect of magnetic shear on improved transport and stability has been observed and will be reported in this Letter. Two different discharge startup scenarios have been developed 
to produce q-profiles with reversed magnetic shear. Both have improved electron particle and thermal diffusivity. In both cases the plasma is initially started at or near full size and ramped up in current at a ramp rate of $1.8 \mathrm{MA} / \mathrm{s}$ to about $1.0 \mathrm{MA}$. For one scenario the rate of rise of the plasma current is reduced to $0.4 \mathrm{MA} / \mathrm{s}$ until the final plasma current of $I_{p}=1.6 \mathrm{MA}$ is reached, as shown in Fig. 1(a). Having a large plasma, while the current is still low and rising, forces the current to form initially at the edge and to diffuse towards the center. Since the current diffusion time is much longer than the rise time of the plasma current, a hollow current density profile is formed. To further slow down the current penetration to the plasma center, neutral beam injection (NBI) begins with a low power "prelude" phase at $\sim 0.6$ seconds, with $5-7.5 \mathrm{MW}$ of power injected into the plasma. This is followed by the main heating phase with up to $25 \mathrm{MW}$ of NBI, as shown in Fig. 1(a). The prelude phase causes the electron temperature to increase from $\sim 2 \mathrm{keV}$ to $\sim 5 \mathrm{keV}$, making the current diffusion time $\sim 10$ seconds. Neutral beam injection, co-tangential to the plasma current, is used in the early phase to drive a significant fraction of the plasma current and further slow the poloidal flux diffusion. Typical q-profiles for this evolution, shown in Fig. 2, have been reconstructed with the VMEC equilibrium code [11] from the MSE data, kinetic pressure data, calculated fast ion pressure from the TRANSP code [12], and external magnetics data. The uncertainties in $q(R)$ are $10 \%$ or less across the profile [13]. The q-profile has $q(0) \geq 4-5$ and $q_{\min } \sim 3$ at $t=2.0 \mathrm{~s}$. Both $q(0)$ and $q_{\text {min }}$ slowly decrease on a time scale of several seconds and reach $q(0) \sim 3-4$ and $q_{\text {min }} \sim 2$ after three seconds of beam heating, consistent with the neoclassical current diffusion rate. This allows for considerable experimental flexibility to determine the target values for $q(0)$ and $q_{\min }$ in the main heating phase of the discharge.

The plasmas formed in the reversed shear configuration, both in the prelude and heating phase, behave as typical supershots [14] at this power, with a central ion temperature of $\sim 20 \mathrm{keV}$, electron temperature of $\sim 6-7 \mathrm{keV}$ and a central electron density of $\sim 4 \times$ $10^{19} \mathrm{~m}^{-3}$. However, above a threshold in neutral beam power, in the range of $\sim 18-25 \mathrm{MW}$, the particle and thermal transport dramatically improves in the plasma core where the shear 
is reversed. The effect is most strongly seen on the particle diffusivity. The central electron density increases from $\sim 4 \times 10^{19} \mathrm{~m}^{-3}$ to $\sim 1.2 \times 10^{20} \mathrm{~m}^{-3}$ in $\sim 0.3$ seconds, as measured by a 10-channel interferometer array and shown in Fig. 3(a). The density profile outside the reversed shear region changes little, resulting in a peaked density profile. The transition from a normal supershot to the highly peaked reversed shear mode, "R/S-mode", occurs abruptly during the discharge, usually $0.2-0.3$ seconds after the start of the main heating phase. Shown in Fig. 4, is the evolution of the central density, with a transition into the $\mathrm{R} / \mathrm{S}$-mode at $t=2.715 \mathrm{~s}$. In a preceding discharge, with a similar reversed shear q-profile, but lower NBI power, the density saturates by 2.7 seconds and no transition occurs, as shown in Fig. 4. In both discharges the main heating phase starts at 2.5 seconds, with the neutral beam power increasing from $7 \mathrm{MW}$ to $19 \mathrm{MW}$ in the plasma that does not exhibit a transition into the R/S-mode and to $25 \mathrm{MW}$ in the plasma which does. In both cases the NBI is near balanced with little measured plasma rotation. The electron and ion temperature profiles also change when the plasma makes the transition into the R/S-mode. The electron temperature increases $\sim 25 \%$ in the core region only, with little change outside, whereas the ion temperature profile is broadened. The resulting pressure profile, including the calculated fast ion contribution, shown in Fig. 3(b), is very peaked with a peaking factor, $F_{p}=p(0) /\langle p\rangle=7.4$, where $p(0)$ is the pressure at the magnetic axis and $\langle p\rangle$ is the volume-averaged pressure. This is larger than the typical peaking factors for supershots of $\sim 5$ and for L-mode discharges of $\sim 3.3$. We do not have q-profile measurements for these two discharges as the MSE measurements were obscured during the heating phase. However, at the end of the prelude phase the measured q-profiles are similar to those shown in Fig. 2.

The second scenario developed for reversed shear configurations on TFTR maintains a constant plasma current at 1.0 MA for one second after the initial current rise, before completing the current ramp up to $1.8 \mathrm{MA}$, as shown in Fig.1(b). This allows more current density to reach the plasma core and reduces $q(0)$ to $1.5-2.0$. A prelude phase with $9 \mathrm{MW}$ of NBI begins at $2.5 \mathrm{~s}$ before the main heating phase, with $16 \mathrm{MW}$, begins at 3.5 seconds. This case has several features that make it well suited for studying the effect of reversed 
shear on transport. The q-profile initially starts out monotonic with $q(0) \sim 1.5$. With the onset of the heating phase $q(0)$ rises and becomes non-monotonic at about $3.7 \mathrm{~s}$. The final value for $q(0)$ is 2.3 and for $q_{\min }$ it is 1.8 after 0.8 seconds. The $q_{m i n}$ radius starts near the magnetic axis and propagates outward for $0.5 \mathrm{~s}$ to $\rho=r / a \sim 0.3$, where $a$ is the plasma minor radius. Coincident with the shear becoming negative, the electron density and temperature begin to increase rapidly. As in the earlier scenario, the electron density increase is significantly greater than the increase in electron temperature. This increase of electron pressure begins at $\sim 3.85 \mathrm{~s}$, near the magnetic axis, at about the time the shear becomes negative, and propagates outward in time, in a similar fashion to the reversed shear region. Shown in Fig. 5 is the electron pressure evolution at several minor radii. The initial rise in the pressure, due to the additional NBI power starting at 3.5 seconds, saturates by 3.8 seconds for the companion discharge that does not have reversed shear. The time of the transition to the R/S-mode for each radial location is indicated by an arrow in Fig. 5 . The location nearest the magnetic axis, at $\rho=0.05$, has a transition into the R/S-mode at $\sim 3.85$ seconds. At radial locations further from the axis there is an increasing delay before the electron pressure begins to increase. Beyond $\rho \sim 0.45$ no change in pressure is observed. Shown in Fig. 6 is the shear evolution at several minor radii. Also indicated in Fig. 6 for each value of $\rho$ is the time at which the improved confinement is observed, such as shown in Fig. 5 for the electron pressure evolution. The increase in the electron density and temperature occurs after the shear has been reduced and not only in the region of reversed shear, but extending into the region of reduced positive shear. The relation between reversed shear and improved transport is not a simple one, as it appears that the threshold in shear varies across the plasma minor radius due to some additional underlying dependencies. In the region beyond $\rho \sim 0.45$ no reduction of shear is measured and no improvement in transport is observed.

The transport analysis using the TRANSP code, from this and previous data, shows that the particle diffusivity drops precipitously in the region of reversed and reduced shear when the R/S-mode begins. The inferred particle diffusivity, assuming no pinch terms, can 
drop by as much as a factor of 50 from $D_{e} \sim 0.25 \mathrm{~m}^{2} / \mathrm{s}$ to near the neoclassical level of $D_{e} \sim 0.005 \mathrm{~m}^{2} / \mathrm{s}$ in the reversed shear region. There is a reduction of a factor of $2-3$ in the ion and electron thermal diffusivity, but not in all discharges. It is not yet apparent what determines the threshold in the magnetic shear or, as in the previous scenario, the injected neutral beam power. Reversed shear appears to be a necessary, but not sufficient condition for the R/S-mode.

The reversed shear plasmas are observed to be free of any coherent, low- $n$ or high- $n$ MHD activity in the region of reversed shear. This includes the discharges with very peaked pressure profiles, and large pressure gradients, $p^{\prime}=d p / d \psi$, which are often the driving mechanism for MHD instabilities. The pressure gradient, $p^{\prime}$ in the $\mathrm{R} / \mathrm{S}$-mode is larger, by a factor of 3-5 than typical TFTR supershots, which often have low- $n$ MHD modes in the plasma core. They are believed to be neoclassical tearing modes [15], which theoretically may be stabilized by reversed shear. Outside the region of reversed shear MHD modes are sometimes present and are currently limiting the stability and performance of the R/S-mode to values of $\beta_{N}^{*}=3.1$, where $\beta^{*} \equiv 2 \mu_{0}<p^{2}>^{1 / 2} / B_{T}^{2}$ and $\beta_{N}^{*}=\beta^{*} a B_{T} / I_{p}(M A)$, with $B_{T}$ the vacuum toroidal field, in Tesla. The discharges with high performance develop low- $n$ MHD modes and possibly a ballooning mode just outside the $q_{\min }$ radius before terminating in a disruption. The exact cause of the disruption is not yet certain and is a subject of ongoing investigation.

In conclusion, highly peaked density and pressure profiles in a new operating regime have been observed on TFTR with a reversed magnetic shear configuration that reduces particle transport by over an order of magnitude to near neoclassical levels. The improved transport is in the region of reversed shear and extends out to the reduced shear region as well. With variations of the neutral beam prelude timing, heating phase timing, and total current, a range of reversed shear configurations has been produced. The safety factor on axis is in the range from $2-5$ and $q_{\min }$ varies from 1.8-3. We expect to further extend the range of $q(0)$ and $q_{\min }$. The stability limit has been tested in only two scenarios to date. According to ideal MHD theory the $\beta_{N}^{*}$ limit is sensitive to the value of $q_{m i n}, q(0)$, and the total plasma 
current. With further optimization we hope to extend the $\beta_{N}^{*}$ limit beyond the present value of 3.1 making the R/S-mode an attractive paradigm for an advanced tokamak reactor.

We would like to thank the TFTR staff for their support and operation of the experiment. This work was supported by United States Department of Energy Contract No. DE-AC0276-CHO-3073. 


\section{REFERENCES}

[1] C. Kessel, J. Manickam, G. Rewoldt, and W. M. Tang, Phys. Rev. Lett. 72, 1212 (1994).

[2] B. B. Kadomtsev and O. P. Pogutse, Soviet Physics JETP 24, 1172 (1967).

[3] A. Sykes, J. A. Wesson, and S. J. Cox, Phys. Rev. Lett. 39, 757 (1977).

[4] R. J. Goldston et al., Plasma Physics and Controlled Fusion 36, B213 (1994).

[5] D. Moreau et al., Plasma Physics and Controlled Nuclear Fusion Research, Würzburg, 1992 (International Atomic Energy Agency, Vienna, 1993), Vol. I, p. 649.

[6] G. L. Schmidt et al., Plasma Physics and Controlled Nuclear Fusion Research, Nice, 1988 (International Atomic Energy Agency, Vienna, 1989), Vol. I, p. 215.

[7] M. Hugon et al., Nucl. Fusion 32, 33 (1992).

[8] D. M. Meade and the TFTR group, Plasma Physics and Controlled Nuclear Fusion Research, Washington, D. C. 1990 (International Atomic Energy Agency, Vienna, 1991), Vol. I, pp. 9-24.

[9] F. M. Levinton et al., Phys. Rev. Lett. 63, 2060 (1989).

[10] F. M. Levinton, Rev. Sci. Instrum. 63, 5157 (1992).

[11] S. P. Hirshman et al., Phys. Plasmas 1, 2277 (1994).

[12] R. J. Hawryluk, Proc. Course in Physics of Plasmas Close to Thermonuclear Conditions, Varenna 1979 (CEC, Brussels, 1980), Vol. I, p. 19.

[13] S. H. Batha et al., Submitted for publication .

[14] J. D. Strachan et al., Phys. Rev. Lett. 58, 1004 (1987).

[15] Z. Chang et al., Nucl. Fusion 34, 1309 (1994). 


\section{FIGURES}

FIG. 1. The plasma current and neutral beam evolution for (a)the first scenario and (b)the second scenario.

FIG. 2. The q-profiles at the beginning of the current flatop at $t=2 \mathrm{~s}$ (dashed line), and near the end of the heating phase at $\mathrm{t}=3.35 \mathrm{~s}$ (solid line) for the first scenario. The profiles are reconstucted by the VMEC equilibrium code and MSE data points are shown at $t=3.35 \mathrm{~s}$.

FIG. 3. The (a)density and (b)pressure profile before the transition to the R/S-mode (dashed line) and at the time of peak density and pressure (solid line).

FIG. 4. The evolution of the electron density at the magnetic axis for a discharge that makes a transition into the $\mathrm{R} / \mathrm{S}-$ mode at $2.715 \mathrm{~s}$ (solid line) and a similar discharge at lower NBI power which does not (dashed line).

FIG. 5. The evolution of the electron pressure at several radial locations for a reversed shear discharge (solid line) and a companion non-reversed shear discharge (dashed line). The onset time of the improved confinement for the reversed shear discharge is indicated with an arrow for each radius.

FIG. 6. The evolution of the shear at several radial locations. The uncertainty of the shear is determined from many runs of the VMEC code with variations of the data within one standard deviation. The onset time of the improved confinement is indicated for each curve. 


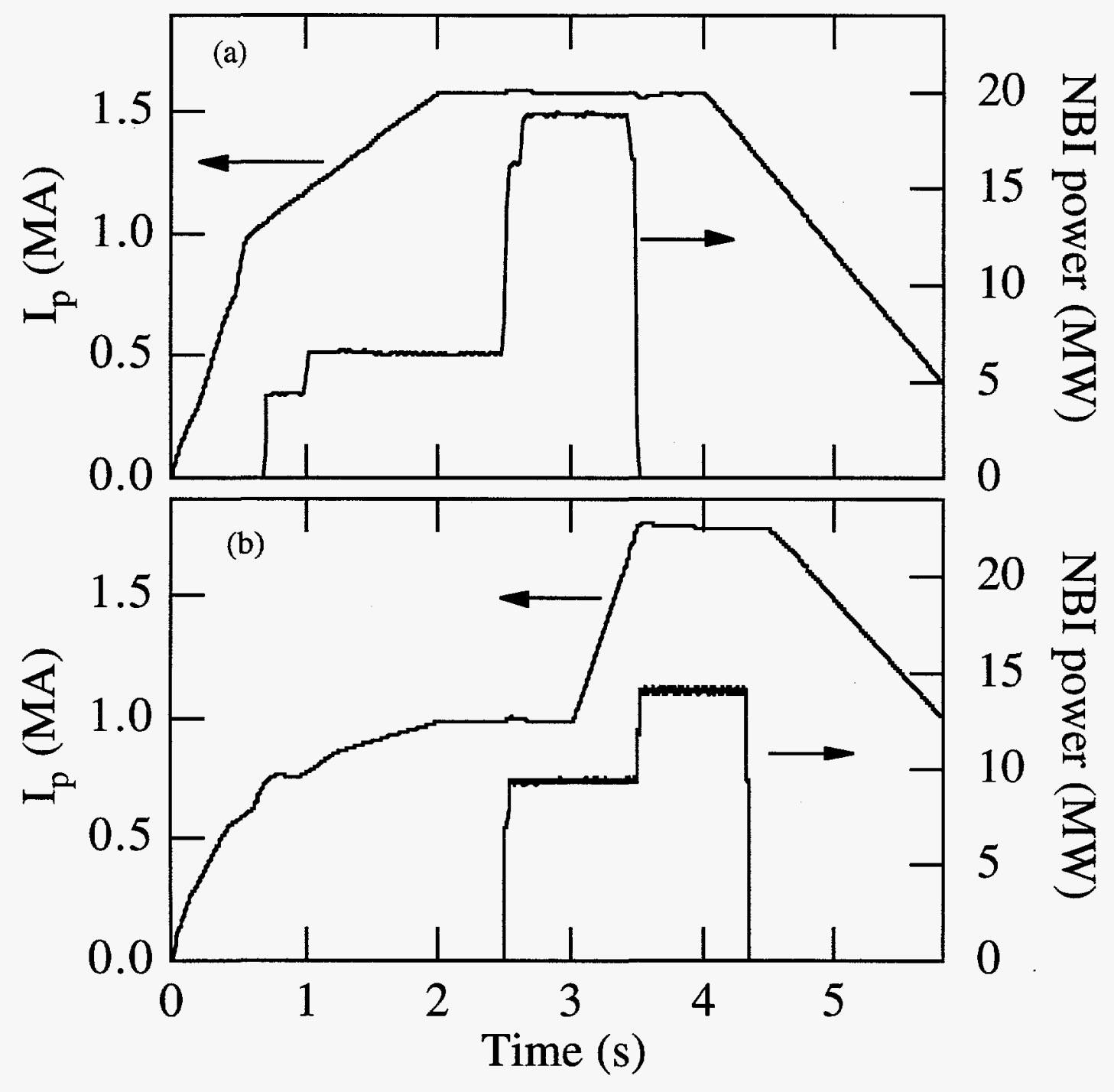

Figure 1. 


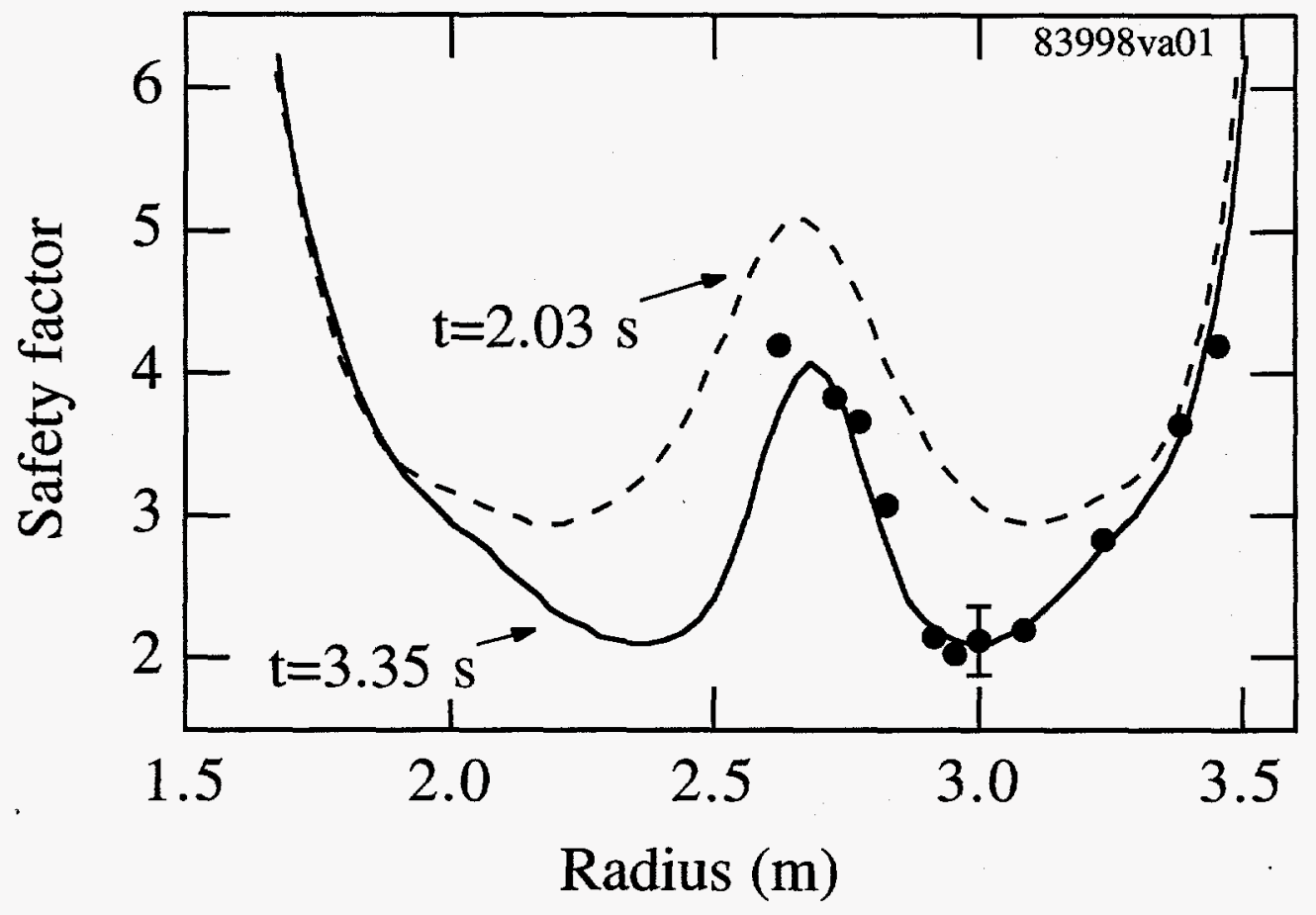

Figure 2. 

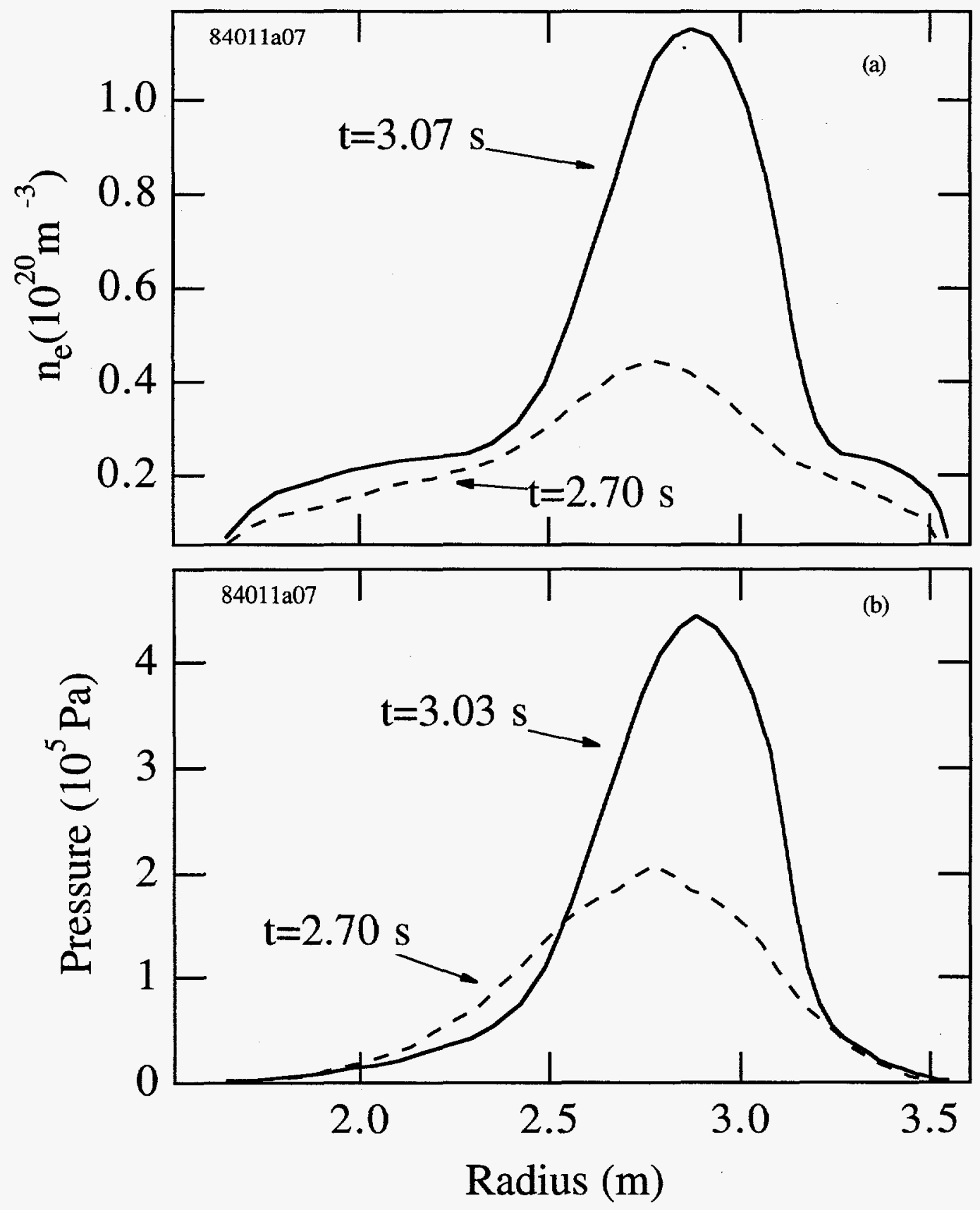

Figure 3. 


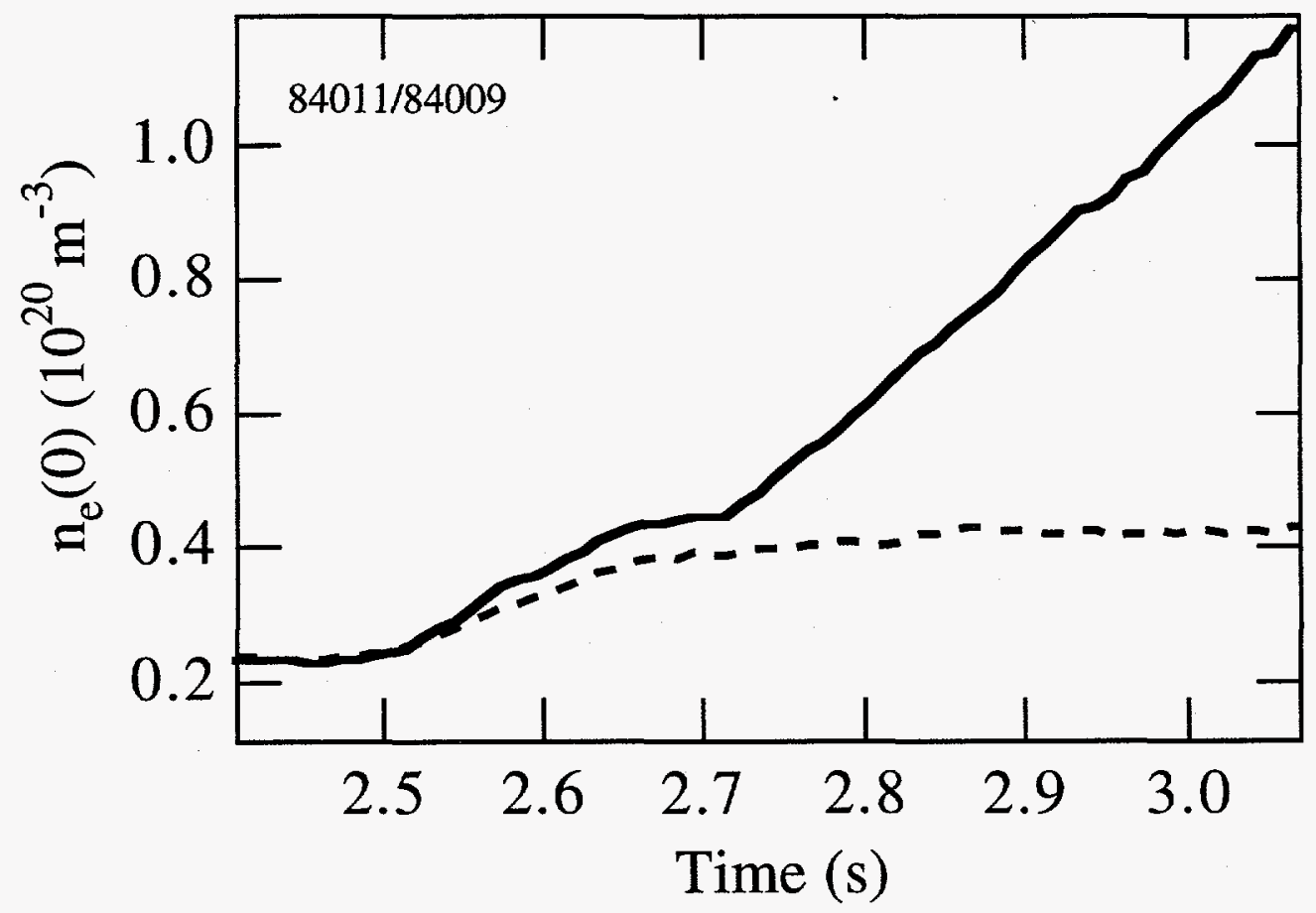

Figure 4. 


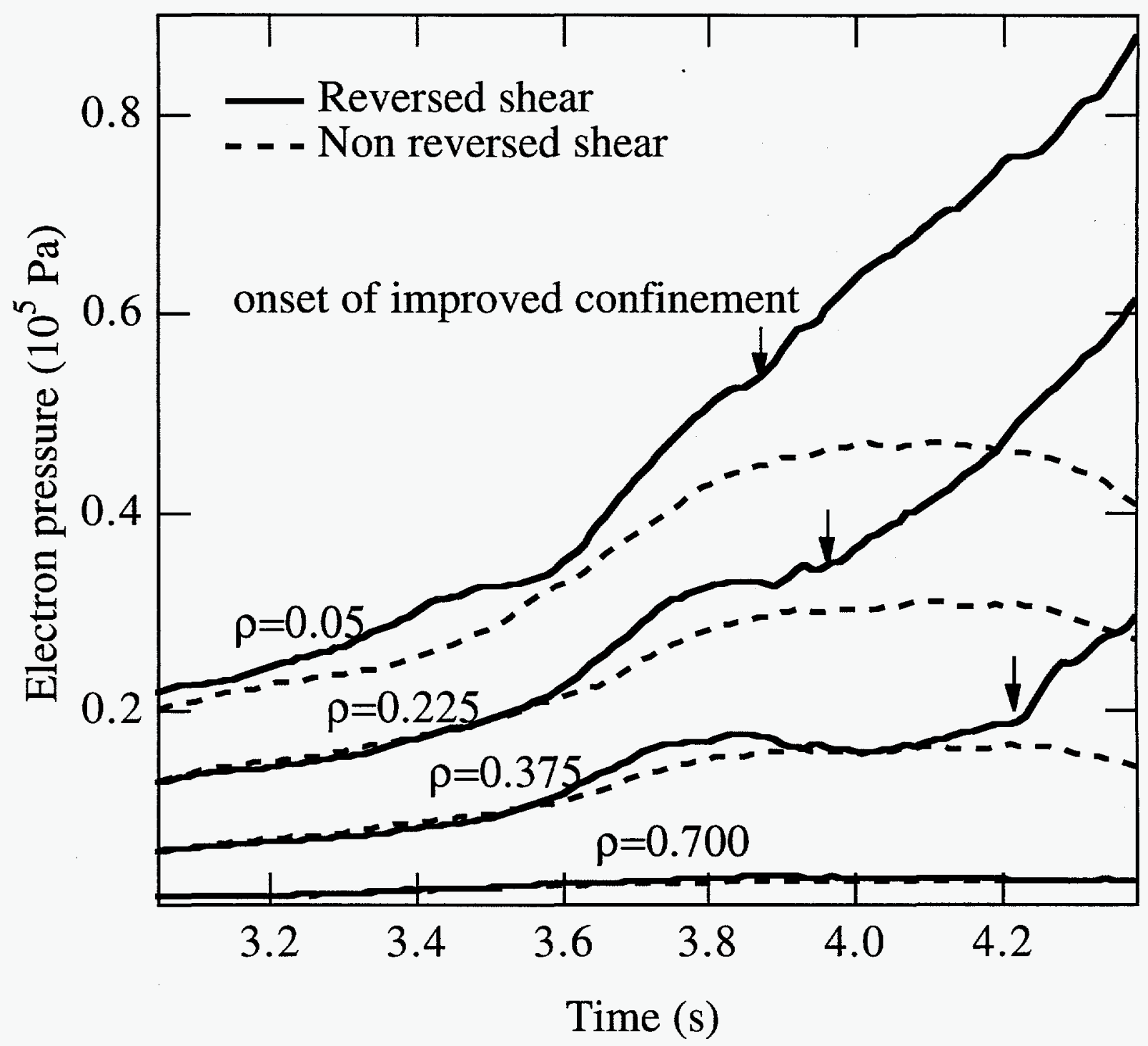

Figure 5 . 


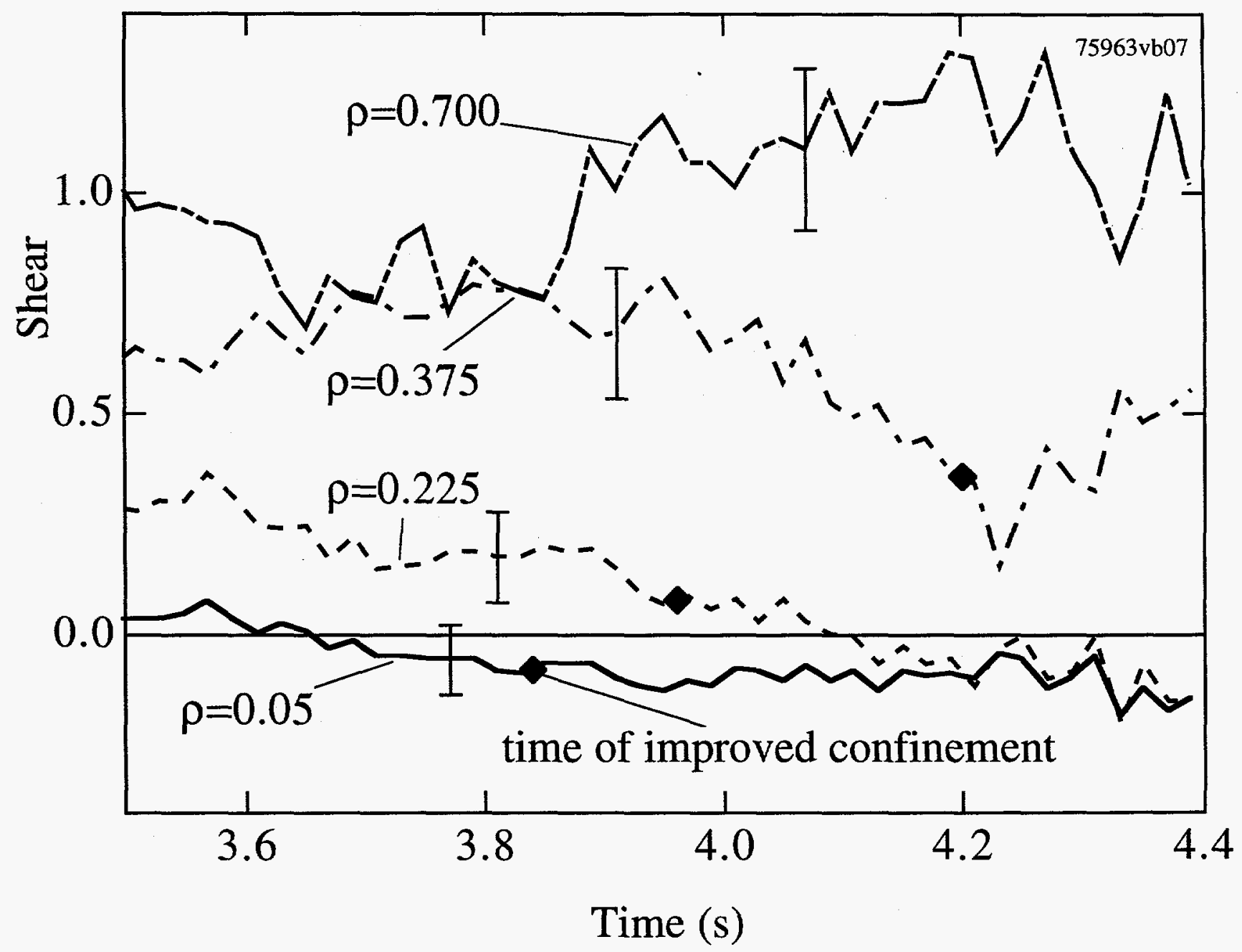

Figure 6. 
Dr. F. Paoloni, Univ. of Wollongong, AUSTRALIA

Prof. R.C. Cross, Univ. of Sydney, AUSTRALIA

Plasma Research Lab., Australian Nat. Univ., AUSTRALIA

Prof. I.R. Jones, Flinders Univ, AUSTRALIA

Prof. F. Cap, Inst for Theoretical Physics, AUSTRIA

Prof. M. Heindler, Institut für Theoretische Physik, AUSTRIA

Prof. M. Goossens, Astronomisch Instituut, BELGIUM

Ecole Royale Militaire, Lab. de Phy. Plasmas, BELGIUM

Commission-European, DG. XII-Fusion Prog., BELGIUM

Prof. R. Boucique, Rijksuniversiteit Gent, BELGIUM

Dr. P.H. Sakanaka, Instituto Fisica, BRAZIL

Prof. Dr. I.C. Nascimento, Instituto Fisica, Sao Paulo, BRAZIL Instituto Nacional De Pesquisas Espaciais-INPE, BRAZIL

Documents Office, Atomic Energy of Canada Lid., CANADA

Ms. M. Morin, CCFWTokamak de Varennes, CANADA

Dr. M.P. Bachynski, MPB Technologies, Inc., CANADA

Dr. H.M. Skarsgard, Univ. of Saskatchewan, CANADA

Prof. J. Teichmann, Univ. of Montreal, CANADA

Prof. S.R. Sreenivasan, Univ. of Calgary, CANADA

Prof. R. Marchand, INRS-Energie et Materiaux, CANADA

Dr. R. Bolton, Centre canadien de fusion magnétique, CANADA

Dr. C.R. James,, Univ. of Alberta, CANADA

Dr. P. Lukác, Komenského Universzita, CZECHO-SLOVAKIA

The Librarian, Culham Laboratory, ENGLAND

Library, R61, Rutherford Appleton Laboratory, ENGLAND

Mrs. S.A. Hutchinson, JET Library, ENGLAND

Dr. S.C. Sharma, Univ. of South Pacific, FIJI ISLANDS

P. Mähönen, Univ. of Helsinki, FINLAND

Prof. M.N. Bussac, Ecole Polytechnique, FRANCE

C. Mouttet, Lab. de Physique des Milieux lonisés, FRANCE

J. Radet, CEN/CADARACHE - Bat 506, FRANCE

Prof. E. Economou, Univ. of Crete, GREECE

Ms. C. Rinni, Univ. of loannina, GREECE

Preprint Library, Hungarian Academy of Sci., HUNGARY

Dr. B. DasGupta, Saha Inst. of Nuclear Physics, INDIA

Dr. P. Kaw, Inst. for Plasma Research, INDIA

Dr. P. Rosenau, Israel inst of Technology, ISRAEL

Librarian, Intemational Center for Theo Physics, ITALY

Miss C. De Palo, Associazione EURATOM-ENEA, ITALY

Dr. G. Grosso, Istituto di Fisica del Plasma, ITALY

Prof. G. Rostangni, istituto Gas lonizzati Del Cnr, ITALY
Dr. H. Yamato, Toshiba Res \& Devel Center, JAPAN

Prof. I. Kawakami, Hiroshima Univ., JAPAN

Prot. K. Nishikawz, Hiroshima Univ., JAPAN

Librarian, Naka Fusion Research Establishment, JAERI, JAPAN

Director, Japan Atomic Energy Research Inst., JAPAN

Prof. S. Itoh, Kyushu Univ., JAPAN

Research Info. Ctr., National Instit. for Fusion Science, JAPAN

Prof. S. Tanaka, Kyoto Univ., JAPAN

Library, Kyoto Univ., JAPAN

Prot. N. Inoue, Univ. of Tokyo, JAPAN

Secretary, Plasma Section, Electrotectnical Lab., JAPAN

Dr. O. Mitarai, Kumamoto Inst. of Technology, JAPAN

Dr. G.S. Lee, Korea Basic Sci. Ctr., KOREA

J. Hyeon-Sook, Korea Atomic Energy Research Inst, KOREA

D.I. Choi, The Korea Adv. Inst. of Sa. \& Tech., KOREA

Leandro Melendez Lugo, Inst. Nacl. de Inves. Nud, MEXICO

Prof. B.S. Liley, Univ. of Waikato, NEW ZEALAND

Inst of Physics, Chinese Acad Sci PEOPLE'S REP. OF CHINA

Library, Inst. of Plasma Physics, PEOPLE'S REP. OF CHINA

Tsinghua Univ. Library, PEOPLE'S REPUBLIC OF CHINA

Z. Li, S.W. Inst Physics, PEOPLE'S REPUBLIC OF CHINA

Prof. J.A.C. Cabral, Instituto Superior Tecnico, PORTUGAL

Prof. M.A. Hellberg, Univ. of Natal, S. AFRICA

Prof. D.E. Kim, Pohang Inst. of Sci. \& Tech., SO. KOREA

Prof. C.I.E.M.A.T, Fusion Division Library, SPAIN

Dr. L. Stenflo, Univ. of UMEA, SWEDEN

Library, Royal Inst. of Technology, SWEDEN

Prof. H. Wilhelmson, Chalmers Univ. of Tech., SWEDEN

Centre Phys. Des Plasmas, Ecole Polytech, SWITZERLAND

Bibliotheek, Inst. Voor Plasma-Fysica, THE NETHERLANDS

Asst. Prof. Dr. S. Cakir, Middle East Tech. Univ., TURKEY

Dr. V.A. Glukhikh,Sci. Res. Inst. Electrophys.I Apparatus, USSR

Dr. D.D. Ryutov, Siberian Branch of Academy of Sci., USSR

Dr. G.A. Eliseev, I.V. Kurchatov Inst., USSR

Librarian, The Ukr.SSR Academy of Sciences, USSR

Dr. L.M. Kovrizhnykh, Inst. of General Physics, USSR

Kemlorschungsanlage GmbH, Zentralbibliothek, W. GERMANY

Bibliothek, Inst. Für Plasmaforschung. W. GERMANY

Prof. K. Schindier, Ruhr-Universitát Bochum, W. GERMANY

Dr. F. Wagner, (ASDEX), Max-Planck-Institut, W. GERMANY

Librarian, Max-Planck-Institut, W. GERMANY 